DOI: $10.17805 /$ zpu.2016.2.24

\title{
Социально-психологические факторы, способствующие и препятствующие первичному отказу от табакокурения (на примере исследования курящих девушек)
}

\author{
А. А. МАКСИМЕНКО, Е.Г. ПИЧУГИНА \\ (КОСТРОМСКОЙ ГОСУДАРСТВЕННЫЙ УНИВЕРСИТЕТ ИМ. Н. А. НЕКРАСОВА)
}

В статье представлены программа и результаты исследования факторов и механизмов, способствующих и препятствующих вовлечению в курение и отказу от него (на примере исследования курящих молодых девушек). В основе данного исследования лежит предположение, что мотивы курения сильно дифференцированы и обусловливают разную расположенность к отказу от курения. Целью исследования является выделение факторов и механизмов, способствующих и препятствующих вовлечению девушек в курение и отказу от него, и выделение на этой основе сегментов курильщиц. Исследование было проведено в 2011-2012 гг., объектом выступили курящие девушки 15-24 лет (жители г. Костромы, Россия). Для сбора эмпирических данных использована авторская анкета «Факторы вовлечения и отказа от курения».

На основании факторного анализа были выделены группы мотивов курения, которые легли в основу сегментации курильщиц. Группы респондентов можно дифференцировать по содержанию компонентов мотивации к табакокурению (имиджмейкеры, гедонисты, социальные, иррациональные курильщицы). Выявлен важный факт изменения мотивации к курению с увеличением стажа: среди курильщиц с наибольшим стажем преобладают «социальные курильщицы» и «курильщицы-гедонисты».

Также были выявлены компоненты мотивации к отказу от табакокурения - негативные физиологические ощущения, разочарование в тех или иных выгодах от курения, осознание нелогичности курения, серьезные заболевания в будущем. При этом для разных групп курильщиц отмечается различный набор стимулов к отказу, что определяет дифференцированный подход к воздействию на курильщиц в рамках антитабачных мероприятий.

Результаты такого исследования могут являться основанием для разработки антитабачных мероприятий. Актуальной и перспективной научной проблемой является изучение социально-психологических факторов первичного отказа от табакокурения и психологических особенностей некурящих людей (потенциальных курильщиков).

Ключевые слова: курение; количественный опрос; отношение к курению; мотивы курения; сегменты курильщиц; отказ от курения

\section{ВВЕАЕНИЕ}

$\mathrm{B}$ последние годы в России активизируется противодействие социально опасным товарам, к которым традиционно можно отнести табачные изделия. После вступления в силу антитабачного закона, по данным Минздрава РФ, число курильщиков в России снизилось на 7,5 млн человек (до уровня 35\% курящих совершеннолетних граждан) (см.: Меркачева, 2015: Электронный ресурс). Однако производители табачных изделий склонны говорить о замещении потребления легально произведенных сигарет на контрабандные, поэтому актуальность проблемы борьбы с табакокурением остается высокой. Наиболее важным аспектом этой борьбы является предотвращение подросткового и молодежного курения.

По результатам глобального опроса взрослого населения о потреблении табака (GATS) (Global Adult Tobacco Survey - Глобального опроса взрослого населения о потреблении табака) в 2009 г. (Глобальный опрос взрослого ..., 2010: Электронный ресурс), в России насчитывается 47\% никогда не куривших людей. При этом у 79\% по- 
требителей табака дебют происходит в возрасте до 20 лет, а после 20 лет вероятность стать курильщиком снижается (2.15. Распределение женщин ... : Электронный ресурс). Как показывает анализ рынка табака, на данный момент сформировался тренд к активной разработке молодежных брендов, что становится дополнительным фактором для вовлечения в курение молодежи.

Мы выделили несколько групп курильщиков молодежи.

1. Потенциальные курильщики - лица, никогда ранее не курившие, но которые могут начать курить.

2. Группа втягивающихся курильщиков - это те, кто только экспериментирует с курением в течение непродолжительного времени, кто находится в стадии пробного потребления.

3. Нерегулярные курильщики - это лица, которые курят эпизодически, не ежедневно. В отличие от втягивающихся курильщиков стаж нерегулярных курильщиков может быть различным - вплоть до очень продолжительного. Курение таких потребителей нередко может быть обусловлено ситуативными факторами.

4. Ежедневные потребители со слабо выраженной зависимостью, со стажем курения менее семи лет ${ }^{1}$.

Поскольку интенсивность вовлечения в табакокурение в этих группах весьма различна, в целях контрмаркетинга целесообразно сегрегированно рассматривать потребителей мужчин и женщин. При том что интенсивность потребления среди мужчин гораздо выше, чем среди женщин, также юноши и молодые люди традиционно более устойчивы к появлению никотиновой зависимости, чем девушки (Никотиновая зависимость развивается ... , 2014: Электронный ресурс). Усилия табачной индустрии устремлены в большей степени на вовлечение женской подростковой аудитории в связи с большей потенциальной емкостью этого сегмента.

Распространенность табакокурения среди девушек и девочек-подростков, по данным опроса «Общенациональный обзор здравоохранения и экономического обеспечения в России», в середине 1980-х годов составляла менее 5\% (Аинамика социальноэкономического ... , 2008). В конце 1990-х годов этот показатель уже перевалил за $12 \%$, а в начале 2000-х превысил $25 \%$ (там же). Подобные сверхвысокие темпы вовлечение молодых женщин в табакокурение обусловили наш выбор молодых курящих девушек в качестве объекта исследования.

\section{ПРОГРАММА ЭМПИРИЧЕСКОГО ИССАЕАОВАНИЯ}

С целью исследования факторов и механизмов, способствующих и препятствующих вовлечению девушек в курение и отказу от него, в течение 2011-2015 гг. нами было проведено исследование. Основным методом эмпирического исследования выступал стандартизированный опрос, который проводился в 2011-2012 гг. В качестве респондентов выступили девушки в возрасте от 15 до 24 лет с разным стажем курения (от 1 месяца до 12 лет, курят не менее одного раза в день) - жительницы российского города Кострома, учащиеся разных учебных заведений. Объем выборки - 350 человек.

Аля достижения цели были определены следующие задачи:

1) определить структуру потребителей по интенсивности и стажу потребления табачных изделий;

2) выявить степень влияния различных мотивов на потребление табачных изделий и латентные факторы, влияющие на потребление;

3) сегментировать потребителей на основании выделенных факторов потребления; 
4) определить преобладающие мотивы отказа от потребления табачных изделий.

Полученные в ходе исследования данные сопровождались математической обработкой с применением процедур непараметрической статистики. Факторный анализ выполнялся методом главных компонент, включающим ортогональное вращение осей (Varimax). Аля определения числа факторов использовались критерии Монте-Карло и Кэттела (scree-test или тест каменистой осыпи). Сегментирование проводилось с помощью метода Варда (иерархической кластеризации). Все процедуры обработки данных производились в программе SPSS 18.0.

Аизайн выборки формировался на основании данных о распространенности потребления табачных изделий (в частности, сигарет) среди учащихся различных учебных заведений (вузов - 36,3\%, ссузов - 45,1\%, школ - 18,6 \%) и разных возрастов (15-17 лет - опрошено 35\%; 18-21 год - 48\%, 22-24 года - 17\%).

В отношении потребления сигарет респондентов можно разделить на втягивающихся $(17,7 \%)$ и ежедневных $(82,3 \%)$ курильщиц. Последние выкуривают от 6 до 30 пачек в месяц, что составляет от половины пачки до одной пачки в день. Втягивающиеся курильщицы курят менее интенсивно: более половины из них выкуривают в месяц менее 5 пачек сигарет, что составляет примерно 3 сигареты в день. Обнаружены положительные корреляции между продолжительностью курения и количеством выкуриваемых пачек сигарет ( $\rho=0,001)$, а также между продолжительностью курения и величиной месячных расходов на покупку сигарет $(\rho=0,001)$.

\section{МОТИВАЦИЯ ТАБАКОКУРЕНИЯ}

Часть опросника была посвящена мотивам курения, респонденты оценивали влияние каждого фактора на потребление табачных изделий по 5-балльной шкале. Выяснилось, что наиболее сильными мотивами курения в среднем по выборке являются возможность через курение снять стресс и расслабиться $(3,55$ балла), а также привычка $(3,45$ балла). Следующие по значимости мотивы курения: зависимость от никотина (2,94 балла) и курение «за компанию» $(2,81$ балла). Такой мотив, как возможность почувствовать себя взрослой и уверенной для усиления привлекательности в глазах противоположного пола, оценен в 1,50 балла.

Эти результаты согласуются с данными разных исследователей, в том числе с самыми последними данными исследования социально-психологического отношения к табакокурению, полученными В. П. Позняковым и В. А. Хромовой (Позняков, Хромова, 2010). Теоретической основой этого исследования выступает концепция психологических отношений индивидуальных и групповых субъектов совместной жизнедеятельности (Позняков, 2000, 2013). С позиций этой концепции в структуре психологического отношения к табакокурению выделяются когнитивный компонент (знание о вреде курения для организма), эмоциональный компонент - эмоциональная оценка феномена «табакокурение», поведенческий компонент - готовность человека отстаивать собственную позицию при взаимодействии с курящим. Так, в результате свободного неформализованного интервью на выборке в 111 курящих респондентов этими авторами получен перечень преимуществ от курения, среди которых релаксация и снятие стрессов $(30,6 \%)$, переживание удовольствия $(18 \%)$; гармонизация душевного мира $(13,5 \%)$, улучшение ситуации общения со знакомыми и незнакомыми людьми $(10,8 \%)$, символизированный фон покоя, отдыха, перерыв в других занятиях $(10,8 \%)$, улучшение умственной деятельности $(10 \%)$, регуляция употребления пищи $(3,6 \%)$ (Позняков, Хромова, 2010: 88-90). 
В нашем исследовании использовалась методика семантического дифференциала, с помощью которой было выявлено, что потребительницы табака стали воспринимать себя более уверенными после начала курения, более взрослыми, общительными, интересными и компанейскими по сравнению с периодом до потребления сигарет. Полученные ответы подтверждаются данными социально-психологических исследований разных авторов, связывающих курение именно с женской эмансипацией, но не с женственностью, и с такой функцией курения, как возможность общения и расширение круга знакомств, снижение психологической дистанции, нахождение взаимопонимания на фоне совместного курения (Кваша, 2007: Электронный ресурс; Позняков, Хромова, 2010). Таким образом, для потребительниц табака социально-психологические функции табакокурения играют весьма существенную роль при вовлечении в курение, выступая определенным средством улучшения общения и снижения психологической дистанции.

Аля определения латентных факторов, опосредованно влияющих на табакокурение, был выполнен факторный анализ по мотивам курения. Первый фактор был нами назван «Капитализация Я-бренда», поскольку он добавлял образ «серьезности» и агрегировал в себя такие переменные, как «сигарета делает меня более деловой», «это выглядит сексуально и нравится молодым людям», «курение для меня - это протест или вызов окружающим», «сигарета помогает ощущать всю полноту жизни», «сигарета помогает мне знакомиться, начинать общение с кем-то». Второй фактор был назван нами «Привычка». Он включает в себя такие переменные, как «у меня выработалась зависимость к никотину», «курю уже автоматически, по привычке», «сигарета помогает мне занять (“убить”) время». Потребители вовлекаются в курение, не имея ярко выраженного стимула для курения, для преодоления монотонности времени вынужденного ожидания. Третий фактор - «Социальный». Он включает в себя переменные солидаризации и конформности: «все мое окружение курит», «я часто курю за компанию», «я не хочу отбиваться от коллектива». В четвертом факторе - «Регуляторе душевного состояния» - объединились такие переменные, как «сигарета помогает мне сконцентрироваться» и «сигарета помогает снять стресс и расслабиться».

\section{СЕГМЕНТАЦИЯ КУРИАЬЩИЦ}

Сегментация потребительниц была произведена на основе кластерного анализа с помощью метода Варда, который позволил выделить четыре группы респондентов, различающихся содержанием мотивов табакокурения на базе ранее выделенных факторов мотивов курения.

Первая группы респондентов, названная нами «социальные курильщицы» $(22,8 \%$ респондентов), объединяет потребительниц табака с явно выраженным стремлением курить «за компанию». У них нет ярко выраженной цели сформировать определенный образ в глазах окружающих или значительно повысить самооценку. Кроме того, им не доставляет удовольствия сам процесс табакокурения, и они больше ориентированы на курение в группе.

Аля второй группы курильщиц («курильщицы-гедонистки» - 31,4\%) наибольшую ценность представляют непосредственно процесс табакокурения и связанные с ним получаемые выгоды: снятие стресса и напряженности, успокоение, расслабление, концентрирование на чем-либо, получение удовольствия от аромата сигарет и дыма. Эти потребительницы могут курить в одиночестве и для себя. Можно отме- 
тить в качестве предположения, что у них уже сформировалась зависимость от курения.

У респонденток третьей группы («иррациональные курильщицы»- 33,7\%) не отмечается ярко выраженных ведущих стимулов к табакокурению (средние значения всех факторов меньше 0). Они курят не по привычке, не автоматически, а вполне осознанно. На уточняющий вопрос: «Почему ты куришь?»- отвечают: «Просто так, но могу бросить в любой момент».

У курильщиц четвертой группы ( «курильщицы-имиджмейкеры» - 12,1\%) наиболее выраженной является мотивация построения собственного имиджа с нотками демонстративности в поведении. Примечательно, что именно у курильщиц-имиджмейкеров отмечается относительно низкое желание бросить курить, что свидетельствует о том, что этот мотив является самым сильным в потреблении табака. В остальных сегментах (группах, выделенных в результате сегментации) у потребительниц табака преобладает сильное желание бросить курить. Так, в среднем по выборке подтвержАают готовность отказаться от табакокурения 64,3\% опрошенных.

Стаж табакокурения в значительной мере взаимосвязан с принадлежностью курильщицы к той или иной группе (данный вывод сделан на основе анализа таблиц сопряженности). В табл. 1 можно увидеть, что с увеличением продолжительности курения изменяется доля социальных курильщиц и курильщиц-гедонисток: от незначительного уровня проявления (9\% и 12\% соответственно) до преобладающего (30\% и $60 \%$ соответственно). Таким образом, можно сделать весьма важный вывод в понимании мотивации табакокурения о миграции сегментов (изменении принадлежности курильщиц от одного сегмента к Аругому): по мере увеличения стажа табакокурения в сторону преобладания таких сегментов, как «социальные курильщицы» и «курильщицы-гедонисты». Поскольку потребительницы этих сегментов отличаются наличием более длительной зависимости от курения, это утверждает нас в необходимости проведения мероприятий превентивного характера.

\section{СТРУКТУРА ПОТРЕБИТЕАЬСКИХ КААСТЕРОВ В ГРУППАХ} С РАЗНЫМ СТАЖЕМ КУРЕНИЯ, \%

Таблица 1

Table 1

THE STRUCTURE OF CONSUMER CLUSTERS IN GROUPS OF SMOKERS WITH VARIOUS LENGTHS OF SMOKING HISTORY, \%

\begin{tabular}{|c|c|c|c|c|c|c|c|}
\hline \multirow{2}{*}{ Кластер } & \multicolumn{7}{|c|}{ Стаж курения } \\
\hline & $\begin{array}{l}\text { менее } \\
6 \text { мес. }\end{array}$ & $\begin{array}{l}\text { om } 6 \text { мес. } \\
\text { до } 1 \text { года }\end{array}$ & 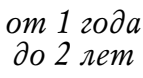 & $\begin{array}{l}\text { om } 2 \text { до } \\
4 \text { nem }\end{array}$ & $\begin{array}{c}\text { om } 4 \text { до } \\
6 \mathrm{nem}\end{array}$ & $\begin{array}{l}\text { om } 6 \text { до } \\
9 \text { лem }\end{array}$ & $\begin{array}{l}\text { более } \\
9 \text { лет }\end{array}$ \\
\hline $\begin{array}{l}\text { Курильщицы- } \\
\text { имиджмейкеры }\end{array}$ & 29 & 20 & 12 & 10 & 7 & 4 & 0 \\
\hline $\begin{array}{c}\text { Иррациональные } \\
\text { курильщицы }\end{array}$ & 50 & 49 & 44 & 30 & 22 & 17 & 10 \\
\hline $\begin{array}{l}\text { Курильщицы- } \\
\text { гедонисты }\end{array}$ & 12 & 15 & 22 & 35 & 42 & 54 & 60 \\
\hline $\begin{array}{l}\text { Социальные } \\
\text { курильщицы }\end{array}$ & 9 & 17 & 22 & 25 & 29 & 25 & 30 \\
\hline Итого & 100 & 100 & 100 & 100 & 100 & 100 & 100 \\
\hline
\end{tabular}


МОТИВАЦИЯ К ОТКАЗУ ОТ КУРЕНИЯ

Изучение мотивов отказа от курения способствует пониманию рычагов воздействия на потребительское поведение курильщиц. В связи с этим наряду с определением наиболее значимых причин отказа от курения, а также и наиболее воспринимаемых недостатков от потребления табака в опроснике использовался вопрос «Каковы наиболее весомые причины Вашего желания бросить курить?», на который был предложен ряд вариантов ответа. Наиболее часто упоминаемые причины возможного отказа от табакокурения в порядке убывания выглядят следующим образом: желание родить здорового ребенка $(81 \%)$, нежелание столкнуться с серьезными заболеваниями сердечно-сосудистой системы и легких $(80 \%)$, ощутимые затраты на приобретение сигарет $(56 \%)$, неприятный въевшийся табачный запах от волос и одежды $(53 \%)$, желание прожить дольше (51\%) и осознание факта зависимости от дурной привычки - курения сигарет (50\%). Отметим, что первые две причины отказа как наиболее возможные выбрали преимущественно потребительницы с длительным стажем курения.

Аля определения латентных факторов отказа от курения был проведен факторный анализ, когда взаимосвязанные переменные были объединены в более общие категории - группы факторов.

Первый фактор, названный нами «настоящие (текущие) негативные физиологические эффекты», включил в себя следующие переменные: проблемы с неприятным запахом изо рта, цветом зубов, видом кожи, кашлем, потеря физической формы. Это результаты влияния табакокурения на организм, которые проявляются даже при небольшой продолжительности потребления.

Такие переменные, как отсутствие стимулов курить дальше, тенденция к отказу от курения в коллективе, угнетающая зависимость, запреты родных, несовременный и вульгарный образ курящей девушки, определили второй фактор, который можно охарактеризовать как «разочарование в выгодах от курения».

K третьему фактору - «осознание нелогичности курения» отнесены переменные: «курение отнимает много денег», «хочу бросить курить ради здоровья будущего ребенка» и «моя одежда и волосы пахнут сигаретами». Название фактора иллюстрирует осознание того, насколько нерационально и нелогично курильщица ведет себя.

И наконец, последний, четвертый фактор состоит из одной переменной - риска серьезных заболеваний, связанных с курением, можно наименовать как «серьезные заболевания в будущем».

В табл. 2 даны средние значения факторов отказа от курения в отдельных потребительских кластерах. Аля курильщиц-имиджмейкеров наиболее значимым фактором являются текущие негативные эффекты, связанные с физическим состоянием и внешним видом. Это можно объяснить тем, что основной стимул табакокурения для имиджмейкеров заключается в построении имиджа. Курильщицы-гедонистки сильно акцентированы на мелкие неприятности, которые уже проявляются от постоянного курения. Однако еще более значимым стимулом для отказа от табакокурения для них являются серьезные заболевания, которые могут проявиться в будущем. «Социальные курильщицы» выделяют текущие неприятности со здоровьем и внешним видом, а также сообщают о своем разочаровании в выгодах от курения. Аля «иррациональных курильщиц» (без определенного стимула к курению) наиважнейшим фактором отказа является осознание и понимание нелогичности курения. 
ФАКТОРЫ ОТКАЗА ОТ КУРЕНИЯ В РАЗРЕЗЕ ПОТРЕБИТЕАЬСКИХ КААСТЕРОВ,

Таблича 2 СРЕАНИЕ ЗНАЧЕНИЯ

Table 2 REASONS FOR QUITTING SMOKING IN THE CONTEXT OF CONSUMER CLUSTERS, MEAN VALUES

\begin{tabular}{|c|c|c|c|c|}
\hline \multirow[b]{2}{*}{ Kracmep } & \multicolumn{4}{|c|}{ Фактор отказа от курения } \\
\hline & $\begin{array}{c}\text { Текушие } \\
\text { негативнье } \\
\text { физиологиче- } \\
\text { ские әффекть }\end{array}$ & $\begin{array}{c}\text { Разочарование } \\
\text { в вьгодах } \\
\text { от курения }\end{array}$ & $\begin{array}{c}\text { Осознание } \\
\text { нелогичности } \\
\text { курения }\end{array}$ & $\begin{array}{c}\text { Риск } \\
\text { серьезных забо- } \\
\text { леваний }\end{array}$ \\
\hline $\begin{array}{l}\text { Социальные } \\
\text { курильщицы }\end{array}$ & 0,035457 & 0,006938 & $-0,134406$ & $-0,065914$ \\
\hline Курильщицы-гедонисты & 0,062259 & $-0,038225$ & 0,045890 & 0,189534 \\
\hline $\begin{array}{c}\text { Иррациональные } \\
\text { курильщицы }\end{array}$ & $-0,179068$ & 0,023429 & 0,074579 & $-0,087990$ \\
\hline $\begin{array}{l}\text { Курильщицы- } \\
\text { имиджмейкеры }\end{array}$ & 0,159508 & $-0,083802$ & 0,010971 & $-0,257750$ \\
\hline
\end{tabular}

Примечание. Расчет средних значений факторов был сделан в программе SPSS 18.0. Факторный анализ выполнялся методом главных компонент, после чего производилось ортогональное вращение осей до линии регрессии, максимизирующее дисперсию и минимизирующее разброс (Varimax).

\section{ЗАКАЮЧЕНИЕ}

Таким образом, полученные в ходе исследования результаты приблизили нас к пониманию мотивации к курению и отказу от него, а также утвердили в необходимости разработки дифференцированных программ антитабачной направленности в отношении молодых курильщиц. Кроме того, весьма важным результатом исследования можно считать миграцию сегментов курильщиц с увеличением стажа курения, что еще раз подтверждает важность акцента на проведение превентивных мер противодействия табакокурению. В дальнейшем целесообразно проводить исследования в области восприятия и оценки потребительницами табака контента рекламных материалов различной направленности с целью выбора наиболее эффективных. Актуальной и перспективной научной проблемой является изучение социально-психологических факторов первичного отказа от табакокурения и психологических особенностей некурящих людей (Позняков, Решетко, 2015).

\section{ПРИМЕЧАНИЕ}

${ }^{1} \mathrm{~K}$ регулярным курильщикам с большим стажем относятся люди более старшего возраста (старше 25-30 лет), здесь же мы рассматриваем только мододых людей до 25-30 лет.

\section{СПИСОК АИТЕРАТУРЫ}

2.15. Распределение женщин и мужчин по возрасту на момент начала курения в 2011 г. [Электронный ресурс] // Федеральная служба государственной статистики PФ. URL: http:// www.gks.ru/bgd/regl/b14_50/IssWWW.exe/Stg/02-15.doc (дата обращения: 10.12.2015). 
Глобальный опрос взрослого населения о потреблении табака. Российская Федерация, 2009 (2010) [Электронный ресурс] // World Health Organization. URL: http://www.who.int/tobacco/ surveillance/ ru_tfi_gatsrussian_countryreport.pdf (дата обращения: 10.12.2015).

Аинамика социально-экономического состояния жителей России (данные контрольного долгосрочного обследования в России, 1992-2006 гг.) (2008). М. : Институт социологии. 103 с.

Кваша, Е. А. (2007) Распространенность и динамика курения среди женщин [Электронный ресурс] // Аемоскоп Weekly. № 305-306, 15-28 октября. URL: http://demoscope.ru/weekly/2007/0305/analit04.php (дата обращения: 10.12.2015).

Меркачева, Е. (2015) Аанные Минздрава: большинство людей в России не курит [Электронный ресурс] // Комсомольская правда. 31 мая. URL: http://www.mk.ru/social/2015/05/31/dannye-minzdrava-bolshinstvo-lyudey-v-rossii-ne-kuryat.html (дата обращения: 10.12.2015).

Никотиновая зависимость развивается у мужчин и женщин по-разному (2014) [Электронный ресурс] // Росбалт. 1 апреля. URL: http://www.rosbalt.ru/style/2014/04/01/1251058.html (дата обращения: 10.12.2015).

Позняков, В. П. (2000) Психологические отношения субъектов экономической деятельности. М. : Институт психологии РАН. 220 с.

Позняков, В. П. (2013) Психологические отношения субъектов совместной жизнедеятельности // Знание. Понимание. Умение. № 1. С. 167-174.

Позняков, В. П., Решетко, С. А. (2015) Анализ социально-психологических исследований по проблеме табакокурения // Знание. Понимание. Умение. № 1. С. 236-243.

Позняков, В. П., Хромова, В. $\Lambda$. (2010) Социально-психологическое исследование отношения к табакокурению. М. : ИзА-во Моск. гуманит. ун-та. 180 с.

Аата поступления: 12.12 .2015 г.

\section{SOCIAL AND PSYCHOLOGICAL INCENTIVES \\ AND OBSTACLES TO YOUNG FEMALES' FIRST GIVING UP SMOKING: A CASE STUDY}

A. A. Maximenko, E. G. Pichugina

(N. A. NeKRasov Kostroma State University)

The article presents the outcomes of a research program and a study of the factors and mechanisms that facilitate or impede taking up or quitting smoking, with young female smokers in the focus of the case study. We started from an assumption that motives for smoking are highly variegated, thus conditioning various degrees of propensity to quit smoking. Our study aimed to describe the incentives and obstacles that influence taking up and quitting smoking, as well as to classify young female smokers into groups. The survey, conducted in 2011-2012, targeted female smokers aged 15-24 and residing in the city of Kostroma, Russia. To collect empirical data, we utilized a specially developed questionnaire titled "Factors contributing to taking up or quitting smoking".

Factor analysis helped us classify female smokers according to their prevailing motives. Groups of smokers could be categorized in accordance with the motivation components into 'image makers', 'hedonist', 'social' and 'irrational' smokers. An important change in the motivation happens with the increase in smoking history: among long-time smokers we find the highest percentage of 'social' smokers and 'hedonists'.

The survey also helped discover that the motives to quit smoking include negative bodily experiences, disappointment in the perceived advantages of smoking, recognizing smoking as illogical behavior and a fear of serious diseases it can contribute to. Different groups of smokers may find various combinations of these motives convincing enough to quit smoking, which calls for a variety of strategies to influence these target categories in anti-smoking campaigns.

The outcomes of our study may prove important for campaign organizers. Studying the social and economic factors of first giving up smoking, as well as the psychological features of potential smokers, remains an urgent and promising research problem.

Keywords: smoking; quantitative survey; attitude towards smoking; motives for smoking; classification of female smokers; giving up smoking 


\section{REFERENCES}

2.15. Raspredelenie zhenshchin i muzhchin po vozrastu na moment nachala kureniia v $2011 \mathrm{~g}$. [Age distribution of male and female smokers at taking up smoking, 2011]. Federal'naia sluzbba gosudarstvennoi statistiki RF [Federal State Statistical Service of the Russian Federation] [online] Available at: http://www.gks.ru/bgd/regl/b14_50/IssWWW.exe/Stg/02-15.doc (access date: 10.12.2015). (In Russ.).

Global'nyi opros vzroslogo naseleniia o potreblenii tabaka. Rossiiskaia Federatsiia, 2009 (2010) [Global Adult Tobacco Survey. Russian Federation, 2009]. World Health Organization [Online] Available at: http://www.who.int/tobacco/surveillance/ ru_tfi_gatsrussian_countryreport.pdf (access date: 10.12.2015). (In Russ.).

Dinamika sotsial'no-ekonomicheskogo sostoianiia zhitelei Rossii (dannye kontrol' nogo dolgosrocbnogo obsledovaniia $v$ Rossii, 1992-2006 gg.) (2008) [The dynamics of social and economic well-being of the population of Russian Federation (according to long-term survey, 1992-2006)]. Moscow, Institute of Sociology, Russian Academy of Sciences. 103 p. (In Russ.).

Kvasha, E. A. (2007) Rasprostranennost' i dinamika kureniia sredi zhenshchin [The prevalence and dynamics of smoking among women]. Demoskop Weekly, no. 305-306, October 15-28 [online] Available at: http://demoscope.ru/weekly/2007/0305/analit04.php (access date: 10.12.2015). (In Russ.).

Merkacheva, E. (2015) Dannye Minzdrava: bol'shinstvo liudei v Rossii ne kurit [Ministry of Healthcare: non-smokers in the majority in Russia]. Komsomol'skaia Pravda, May 31 [Online] Available at: http://www.mk.ru/social/2015/05/31/dannye-minzdrava-bolshinstvo-lyudey-v-rossiine-kuryat.html (access date: 10.12.2015). (In Russ.).

Nikotinovaia zavisimost' razvivaetsia u muzhchin i zhenshchin po-raznomu (2014) [Tobacco dependence is formed differently in males and females]. Rosbalt, April 1 [online] Available at: http://www.rosbalt.ru/style/2014/04/01/1251058.html (access date: 10.12.2015). (In Russ.).

Pozniakov, V. P. (2000) Psikhologicheskie otnosheniia sub'ektov ekonomicheskoi deiatel'nosti [Psychological relations between the subjects of economic activity]. Moscow, Publishing House of the Institute of Psychology, RAS. 220 p. (In Russ.).

Pozniakov, V. P. (2013) Psichologicheskie otnosheniia sub'ektov sovmestnoi zhiznedeiatel'nosti [Psychological attitudes of the subjects of joint activity]. Znanie. Ponimanie. Umenie, no. 1, pp. 167-174. (In Russ.).

Poznyakov, V. P. and Reshetko, S. A. (2015) Analiz sotsial'no-psikhologicheskikh issledovanii po probleme tabakokurenia [Social and psychological research on tobacco smoking: A review article]. Znanie. Ponimanie. Umenie, no. 1, pp. 236-243. (In Russ.). DOI: 10.17805/zpu.2015.1.22

Pozniakov, V. P. and Khromova, V. L. (2010) Sotsial' no-psikbologicheskoe issledovanie otnosheniia $k$ tabakokureniiu [Socio-psychological research of attitudes to tobacco smoking]. Moscow, Moscow University for the Humanities Publ. 178 p. (In Russ.).

Submission date: 12.12 .2015

Максименко Александр Александрович - кандидат психологических наук, доцент кафедры менеджмента, маркетинга и коммерции Костромского государственного университета им. Н. А. Некрасова. Адрес: 156000, Россия, г. Кострома, ул. 1 Мая, д. 14. Тел./ факс: +7 (4942) 39-16-35. Эл. адрес: maximenko.al@gmail.com

Пичугина Екатерина Георгиевна - кандидат экономических наук, старший преподаватель кафедры менеджмента, маркетинга и коммерции Костромского государственного университета им. Н. А. Некрасова. Адрес: 156000, Россия, г. Кострома, ул. 1 Мая, д. 14. Тел.: +7 (4942) 39-16-35. Эл. aspec: kate-pichugina@mail.ru

Maksimenko Aleksandr Aleksandrovich, Candidate of Psychology, Associate Professor, Department of management, marketing and commerce, N.A. Nekrasov Kostroma State University. Postal address: 14 1st May St., Kostroma, Russian Federation 156000. Tel.: +7 (4942) 39-16-35. E-mail: maximenko.al@gmail.com 
Pichugina Ekaterina Georgievna, Candidate of Economics, Senior Lecturer, Department of management, marketing and commerce, N.A. Nekrasov Kostroma State University. Postal address: 14 1st May St., Kostroma, Russian Federation 156000. Tel.: +7 (4942) 39-16-35. E-mail: kate-pichugina@mail.ru 